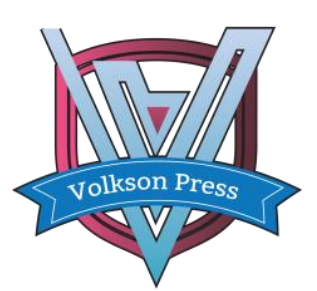

Contents List available at VOLKSON PRESS

Economics \& Management Innovations(EMI)

DOI : http://doi.org/10.26480/icemi.01.2017.343.348

\title{
Cost model of an innovative company based on outsourcing and agile methods
}

\section{Tomasz Chlebus ${ }^{1,}{ }^{*}$, Arkadiusz Kowalski ${ }^{2}$ and Mateusz Minkus ${ }^{1}$}

${ }^{1}$ Faculty of Computer Science and Management, Wrocław University of Science and Technology,

27 Wybrzeże Wyspiańskiego, 50-370 Wrocław, Poland

${ }^{2}$ Faculty of Mechanical Engineering, Wrocław University of Science and Technology,

27 Wybrzeże Wyspiańskiego, 50-370 Wrocław, Poland

*tomasz.chlebus@pwr.edu.pl

This is an open access article distributed under the Creative Commons Attribution License, which permits unrestricted use, distribution, and reproduction in any medium, provided the original work is properly cited.

\section{ARTICLE DETAILS}

\section{Article History:}

Received 02 october 2017

Accepted 06 october 2017

Available online 11 october 2017

\section{Keywords:}

innovative enterprise, costs, computational model, cost estimation,

\section{ABSTRACT}

The paper describes a logistic model of an enterprise based on outsourcing and the agile methods. The purpose of this model is reduction of risk in conditions of business uncertainty. The model was constructed in order to place as much as possible cost sources outside the enterprise. In the paper, two groups of processes are described: product design and supply chain management. The design process is so built that cost sources are located at the customer. In certain sectors, it is possible to create also an additional value and increase the customer's satisfaction. It is described how to set the customer as a designer and to create a system protecting against design errors. On the example of this process, estimation of process costs is described.

\section{Introduction}

A common problem of innovations is their market unpredictability leading to the fact that many ideas even are not attempted to be realized [1]. A potential risk and entry costs seam to be unacceptable to the authors of the ideas and their behaviour [2]. A part of the realized ideas collapse, since they depart from needs or tastes of the customers, while the others achieve too big success and the enterprises delivering the innovative products based on these ideas are unable to satisfy the demand [3], [4].

This paper is aimed at presenting a computational model of costs thanks to that an innovative enterprise will be able to find a response to the mentioned difficulties and, in consequence, to make profit on its ideas. Objectives of the model include:

- reduction of entry costs,

- reduction of investment risk,

- minimisation of break-even point

- use of partners' technical base,

- negative cash conversion cycle,

- reduction of production time,

- reduction of product design costs.

In the cost model of an innovative enterprise, the following processes were modelled: product design and auxiliary actions, like accountancy.

\section{Suggested model of an innovative enterprise}

The model assumes that, to reduce entry costs, investment risk and breakeven point, no new infrastructure is built, but partners having adequate resources are acquired. Investment risk includes also insufficient possibilities of the enterprise that are unable to satisfy the demand, so its potential competition gains development opportunities. In this situation, outsourcing is also a solution, since it is usually easier and faster to establish cooperation with another partner than to build another production enterprise [5], [6], [7]. This is a good solution, especially when it is not sure, whether it is a momentary jump of demand [8]. Moreover, the model assumes that customers are actively involved in the product design [9], since "Happy users perfectly perform the functions for that, in another case, employers should remunerate employees. It can be said that it is not so much outsourcing as crowdsourcing" [10]. On the grounds of the above assumptions, the enterprise model shown in figure 1 is suggested.

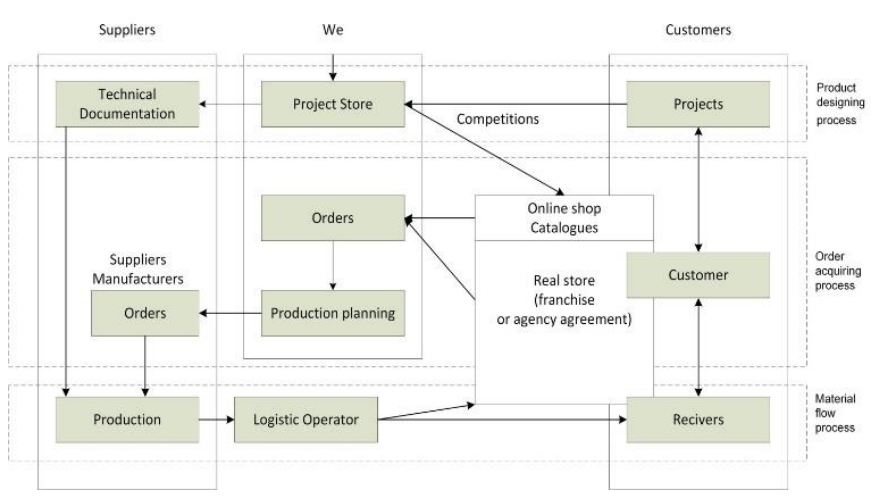

Fig. 1. Suggested model of an innovative enterprise

Realisation of auxiliary objectives is not directly included in the model, but results from favourable agreements with partners. The enterprise is only an intermediary between the users and the manufacturers, and the intermediation is limited to payments and information exchange only. The so run company has a structure named "virtual organisation" and the system based on its relations with partners can be defined as "virtual supply chain" [11], [12], [13].

\subsection{Cost estimation}

In order to estimate costs of running a business, one should be able to determine costs of individual actions and probability of their successful completion:

$$
\mathrm{P}(\mathrm{Y}(\mathrm{Z})=0 \mid \mathrm{U}(\mathrm{Z}))+\mathrm{P}(\mathrm{Y}(\mathrm{Z})=1 \mid \mathrm{U}(\mathrm{Z}))=1 .
$$

where: $C(Z)$ - expected cost of execution of the task Z; $Y(Z)$ - result of the task Z; $\mathrm{Y}(\mathrm{Z})=0$ if the task $\mathrm{Z}$ was executed incorrectly; $\mathrm{Y}(\mathrm{Z})=1$ if the task $\mathrm{Z}$ was executed correctly; $\mathrm{U}(\mathrm{Z})$ - verification whether the task $\mathrm{Z}$ entered correctly; $\mathrm{U}(\mathrm{Z})=0$ if entry of the task $\mathrm{Z}$ was prepared incorrectly; $\mathrm{U}(\mathrm{Z})=1$ if entry of the task $\mathrm{Z}$ was prepared correctly; $\mathrm{P}(\mathrm{Y}(\mathrm{Z}) \mid \mathrm{U}(\mathrm{Z})$ ) - probability of 
execution of the task $\mathrm{Z}$ with the result $\mathrm{Y}(\mathrm{Z})$ provided that correctness condition of the task $\mathrm{Z}$ is $\mathrm{U}(\mathrm{Z})$.

It comes out of the relation (1) that the result will be certainly correct or incorrect. In the calculations, one of these values can be omitted, since it can be simply determined on the ground of the other one. Therefore, probability of obtaining a correct result and its cost only will be treated as characteristics of the task.

In the process structure, 3 basic structures can be distinguished: series of actions, parallel actions and iterative loops. Each of them can be presented as a single task with its characteristics resulting from properties of component tasks and type of the reduced structure:

1. Series of actions - acc. to figure 2 .

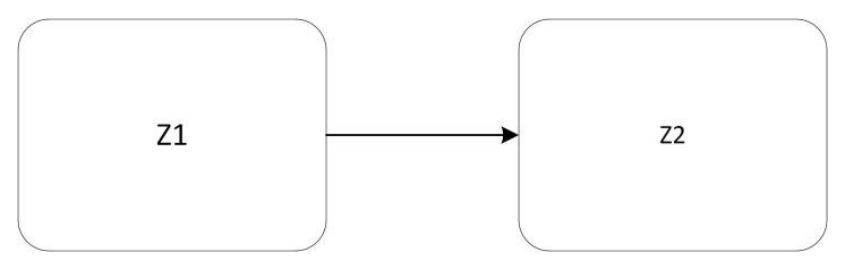

Fig. 2. Schematic presentation of a series of actions

With use of the property (2), the series of actions S presented above can be treated as a single task:

$Y(Z 1)=U(Z 2)$.

Result of the preceding task is an entry to the subsequent task. The series $\mathrm{S}$ can be treated as a task with the following parameters:

$\mathrm{Y}(\mathrm{S})=\mathrm{Y}(\mathrm{Z} 2)$

Result of the last task is the result of the entire series:

$\mathrm{U}(\mathrm{S})=\mathrm{U}(\mathrm{Z} 1)$.

Entry of the first task is the entry of the entire series:

$\mathrm{C}(\mathrm{S})=\mathrm{C}(\mathrm{Z} 1)+\mathrm{C}(\mathrm{Z} 2)$

According to [14], expected cost of execution of the entire series of actions S:

$$
\begin{gathered}
\mathrm{P}(\mathrm{Y}(\mathrm{S})=1 \mid \mathrm{U}(\mathrm{Z} 1))=\mathrm{P}(\mathrm{Y}(\mathrm{Z} 1)=0 \mid \mathrm{U}(\mathrm{Z} 1)) \mathrm{P}(\mathrm{Y}(\mathrm{Z} 2)=1 \mid \mathrm{U}(\mathrm{Z} 2)=0)+ \\
+\mathrm{P}(\mathrm{Y}(\mathrm{Z} 1)=1 \mid \mathrm{U}(\mathrm{Z} 1)) \mathrm{P}(\mathrm{Y}(\mathrm{Z} 2)=1 \mid \mathrm{U}(\mathrm{Z} 2)=0) .
\end{gathered}
$$

Probability of correct execution of the series of actions S.

\section{Parallel actions - acc. to figure 3.}

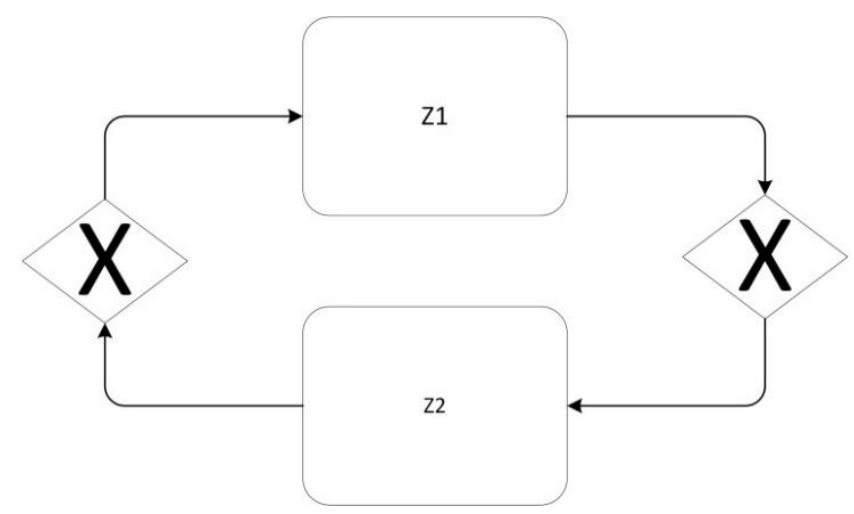

Fig. 3. Schematic presentation of parallel actions

In the case of parallel actions, not always all the actions will be executed. Some of them are dependent on the condition of the separating gateway. For example, when parallel production of a product modules is ordered, some versions of the final product can possess not all options (e.g. a passenger van can be equipped with rear seats and there are no rear seats in a delivery version), so the related parts need not be always produced.
Therefore, for correct cost estimation of parallel actions it is necessary to determine probability of fulfilling the gateway condition for each path, and thus to determine frequency of passing each path. For parallel actions $\mathrm{R}$ composed of the tasks from $\mathrm{Z} 1$ to $\mathrm{Zn}$, expected execution cost is:

$\mathrm{C}(\mathrm{R})=\sum_{\mathrm{i}=1}^{\mathrm{n}} \mathrm{P}(\mathrm{Y}(\mathrm{B}, \mathrm{i})) \mathrm{C}(\mathrm{Zi}) \mathrm{Y}(\mathrm{B}, \mathrm{i})$.

where: $B$ - task of a separating gateway; $U(B)=Y(B)$ - correctness of the result of the actions preceding the gateway; $Y(B, i)=0$ means the decision not to pass $\mathrm{i}$-th path; $\mathrm{Y}(\mathrm{B}, \mathrm{i})=1$ means the decision to pass $\mathrm{i}$-th path; $\mathrm{P}(\mathrm{Y}(\mathrm{B}, \mathrm{i}))$ - probability of selecting i-th path.

Expected cost of task branching. Probability of a correct result of branching of the tasks $\mathrm{R}$ depends on the condition of the merging gateway. For example, if the product modules are manufactured in parallel, all the modules must be good to be assembled in a finished product after merging the process path. However, if a few teams are working on a design of the new product in order that the best of them will be implemented, it is enough that one of the solutions is correct. This results in diversity of the merging conditions. On the assumption that the merging gateway is described by the condition $\mathrm{Y}(\mathrm{R})=\mathrm{Y}(\mathrm{Y}(\mathrm{Z} 1), \mathrm{Y}(\mathrm{Z} 2), \ldots, \mathrm{Y}(\mathrm{Zn}))$, probability of correct execution of parallel tasks is:

$$
\begin{aligned}
& P(Y(R) \mid U(B))=\sum_{j \in D} Y(j) \prod_{i=1}^{n} P(Y(Z i)=1)^{Y(Z i)} P(Y(Z i)=0)^{1-Y(Z i)} \\
& \mathrm{D}=\left\{\mathrm{j}:\left(\forall \mathrm{i} \in \mathrm{N}_{+}, \mathrm{i} \leq \mathrm{n}: \mathrm{W}(\mathrm{Zi}) \in\{0 ; 1\}\right)\right\} .
\end{aligned}
$$

3. Iterative loops - acc. to figure 4 .

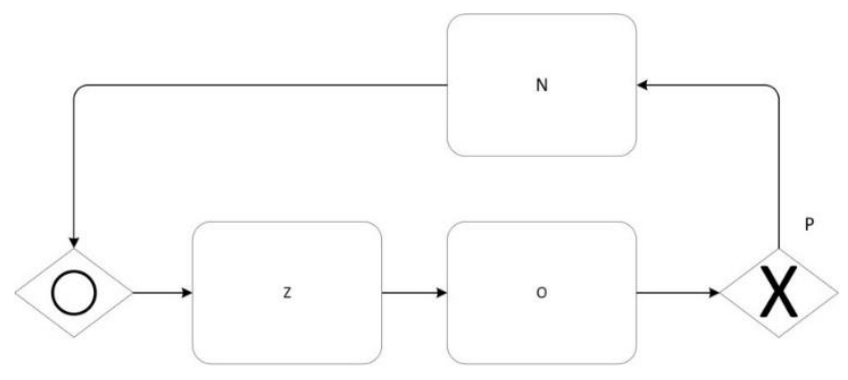

Fig. 4. Schematic presentation of a control loop

The loops occur most often, when an action is subjected to evaluation O. A negative result of the evaluation results in undertaking remedial actions $\mathrm{N}$, whose result is again subjected to evaluation. It is assumed that the evaluation $\mathrm{O}$ controls the decisive gateway B but does not execute any operation on the examined object, so it does not affect its condition. Description of the evaluation will be interpreted in different way than description of the other tasks. $\mathrm{P}(\mathrm{Y}(\mathrm{O}) \mid \mathrm{U}(0))$ means probability of acknowledging the object in the condition $U(0)$ as the object in the condition $\mathrm{Y}(0)$. The gateway B should have at least 3 exits:

- evaluation: correct - continuation of normal run of the process,

- evaluation: incorrect - return (visible in the diagram), iterative corrections in the loop,

- evaluation: incorrect - omission of further corrections within this improvement loop.

Procedures for an incompatible product can define additional conditions of stop, like exceeded time limit, exceeded budget and exceeded determined number of iterations. If the time and cost of one loop cycle can be estimated, these conditions may be reduced to one of them. It is accepted for convenience, that the stop condition is given as maximum number of iterations.

To the functions $\mathrm{U}(\mathrm{Z})$ and $\mathrm{Y}(\mathrm{Z})$, an additional parameter of the iteration number is added. In the notation, they will be $\mathrm{U}(\mathrm{Z}, \mathrm{i})$ and $\mathrm{Y}(\mathrm{Z}, \mathrm{i})$. It is assumed that $\mathrm{Y}(\mathrm{B})$ means number of the exit path; $\mathrm{P}(\mathrm{Y}(\mathrm{B}) \mid \mathrm{Y}(\mathrm{O}), \mathrm{i})$ is probability of choosing the path $Y(B)$ on condition of the evaluation $Y(0)$ after $i$-th iteration of the loop; $i=0$ means the first entry into the loop. Before the first turn, cost of a single loop cycle is:

$\mathrm{C}(\mathrm{P}, \mathrm{i}=0)=\mathrm{C}(\mathrm{Z})+\mathrm{C}(0)$.

Cost of the first iteration cycle:

$\mathrm{C}(\mathrm{P}, \mathrm{i}>0)=\mathrm{C}(\mathrm{Z})+\mathrm{C}(\mathrm{O})+\mathrm{C}(\mathrm{N})$. 
Cost of the subsequent iteration cycle. Probability of a subsequent iteration cycle:

$\mathrm{P}(\mathrm{Y}(\mathrm{B})=2 \mid \mathrm{i})=\mathrm{P}(\mathrm{Y}(\mathrm{B})=2 \mid \mathrm{Y}(0)=0, \mathrm{i})+\mathrm{P}(\mathrm{Y}(\mathrm{B})=2 \mid \mathrm{Y}(0)=1, \mathrm{i})$

Probability of (i+1)-th iteration cycle. Probability of correct result of the loop:

$\mathrm{P}(\mathrm{Y}(\mathrm{B})=1 \mid \mathrm{Y}(0)=1)=\sum_{\mathrm{i}=0}^{\infty} \mathrm{P}(\mathrm{Y}(\mathrm{B})=1 \mid \mathrm{Y}(0)=1, \mathrm{i}) \mathrm{P}(\mathrm{Y}(\mathrm{B})=2 \mid \mathrm{i}-1)$.

Probability of correct result of the loop in i-th iteration. Probability of evaluation of the result as $\mathrm{Y}(0)$ :

$\mathrm{P}(\mathrm{Y}(\mathrm{O}) \mid \mathrm{i})=\mathrm{P}(\mathrm{Y}(0) \mid \mathrm{U}(0)=0, \mathrm{i})+\mathrm{P}(\mathrm{Y}(0) \mid \mathrm{U}(0)=1, \mathrm{i})$,

$\mathrm{Y}(\mathrm{Z})=\mathrm{U}(0)$.

Probability of evaluation of the result as $Y(O)$. Probability of execution of the task with the condition $\mathrm{Y}(\mathrm{Z})$ :

$\mathrm{P}(\mathrm{Y}(\mathrm{Z}) \mid \mathrm{i})=\mathrm{P}(\mathrm{Y}(\mathrm{Z}) \mid \mathrm{U}(\mathrm{Z})=0, \mathrm{i})+\mathrm{P}(\mathrm{Y}(\mathrm{Z}) \mid \mathrm{U}(\mathrm{Z})=1, \mathrm{i})$.

Probability of execution of the task with the condition $Y(Z)$, for $i \geq 1$ :

$\mathrm{U}(\mathrm{Z}, \mathrm{i})=\mathrm{Y}(\mathrm{N}, \mathrm{i})$.

Entry for the first task in the loop is equal to exit of the last task from the previous iteration. Probability of the result of remedial actions equal to $\mathrm{Y}(\mathrm{N})$

$\mathrm{P}(\mathrm{Y}(\mathrm{N}) \mid \mathrm{i})=\mathrm{P}(\mathrm{Y}(\mathrm{N}) \mid \mathrm{Y}(\mathrm{Z})=0, \mathrm{i})+\mathrm{P}(\mathrm{Y}(\mathrm{N}) \mid \mathrm{Y}(\mathrm{Z})=1, \mathrm{i})$.

Probability of the result of remedial actions equal to $Y(N)$. Average number of loop iterations:

$\mathrm{n}=\sum_{\mathrm{i}=0}^{\infty} \mathrm{i} \cdot \mathrm{P}(\mathrm{Y}(\mathrm{B})=2 \mid \mathrm{i})$.

Average cost of execution of the loop P:

$(P)=(n+1)(C(Z)+C(0))+n C(N)$.

\section{Modelled processes}

\subsection{Product design}

Product design according to EN ISO 9001:2009 consists of the established stages and specific actions should be determined for each of them:

- review - i.e. checking, whether the design works are performed according to the plan and with the planning art,

- verification - i.e. checking, whether the design presents what was intended to be designed (in the standard language - comparison of the input and output data),

- validation - i.e. checking, whether the designed product can correctly execute the tasks for that it is created [15], [16].

The design itself should be preceded by collecting information about the requirements imposed to the product by the customers and law, as well as resulting from strategy and technologies applied in the enterprise (socalled internal requirements). On this occasion, it is worth to pay attention to the approach "User Center Design" [17], suggested in the IT field, where designing is performed in cycles and requirements are up-dated in each of them. So, at this approach, determination of requirements is a part of the design process [18].

\subsection{Model assumptions related to characteristics and target nature of the offer}

When lack of knowledge about complete potential of the innovative product idea is taken into account, it can appear that a valuable market can exist, not considered by the creators of the idea or maybe unknown to them. So, it is worth to think about application of the solutions based on the long tail idea that assumes the following:

- number of goods in the supply is much larger than it appears (the tail is long),

- this phenomenon can be successfully used for functioning of the company,
- total of all market niches makes a significant market [10].

On the other hand, one can not deceive oneself that, when interest in a product appears, it will be always long-lasting. When a customer is acquired, 2 situations are possible:

1. After receiving one order, the customer finds that, unfortunately, this idea in completely useless for him and he resigns further orders.

2. The customer notices additional possibilities and needs a modified product, when is back to place a new order.

3. The customer is satisfied of what he received and places new orders for the same products.

The most desirable, from the viewpoint of the enterprise, is the situation No. 3, so it is worth to build the design process in such a way that the situation No. 2 possibly soon gives up its place to the situation No. 3. In this model, general idea of product development will be based on the following assumptions:

- The offer contains many products:

- a part of them was never and will never be manufactured and marketed,

- many of them will be ordered irregularly and rather in small quantities,

few of them will reach a stable demand.

- At the design, participation of the customer's representatives is maximised. Engaging them at the stage of formulating requirements and validation should be obvious, but they could be also involved in the other design stages.

- The design process should guarantee the possibility to join the products into a relatively small number of groups with stable accumulated demand, with the criterion of allocation to the groups considering, first of all, technological similarity of their manufacture. This will allow organisation of the production lines with productivity approximate to that in homogeneous mass production.

\subsection{Estimated design costs}

With respect to expected small sales volume of most of the products, costs of design can make a significant part of indirect costs assigned to a single piece. A generalised diagram of the design proves is shown in figure 5.

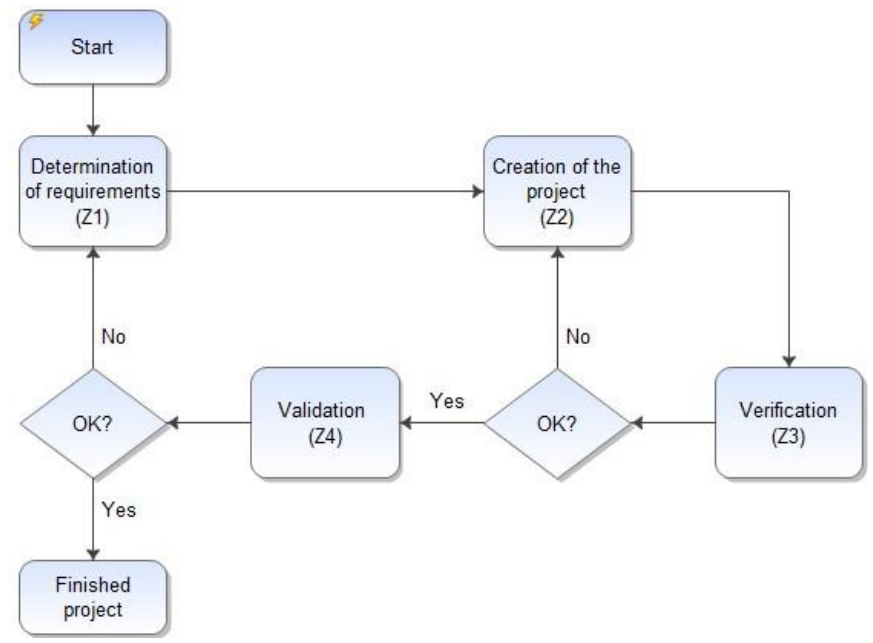

Fig. 5. Map of the design process on the ground of EN ISO 9001:2009

It is worth to think, if it would not be profitable to reduce a bit quality of the design process - lower quality of the project could result in its lower costs but, on the other hand, it could negatively affect price of the finished product or the demand.

\subsection{Assumptions for the estimates}

Complex tasks can be noted as a set of component tasks, e.g. if a complex task is composed of the tasks Z1, Z2 and Z3, it will be noted as $\{\mathrm{Z1} ; \mathrm{Z2} ; \mathrm{Z} 3\}$. Estimation will be performed at the following simplifying assumptions: The tasks can not repair the previously committed errors.

$\mathrm{P}(\mathrm{Y}(\mathrm{Z})=1 \mid \mathrm{U}(\mathrm{Z})=0)=0$. 
- It is assumed for control tasks equal probability of the following control errors:

- acceptance of improper projects as correct,

- acceptance of correct projects as improper.

$\mathrm{P}(\mathrm{Y}(0)=1 \mid \mathrm{U}(0)=0)=\mathrm{P}(\mathrm{Y}(0)=0 \mid \mathrm{U}(0)=1)$

- $\quad$ Cost of the task execution does not change in the subsequent loops of the project execution:

$\forall \mathrm{i}, \mathrm{j}: \mathrm{C}(\mathrm{Z}, \mathrm{i})=\mathrm{C}(\mathrm{Z}, \mathrm{j})$.

- Design is always finished with an accepted project, even if this process should be executed endlessly.

With these simplifications, simplified designations can be accepted. Probability of correct execution of the task will be designated as:

$$
\mathrm{p}_{\mathrm{i}}=\mathrm{P}(\mathrm{Y}(\mathrm{Zi})=1 \mid \mathrm{U}(\mathrm{Zi})=1) .
$$

In the probability index of a complex task, indices of all the component tasks appear in sequence. The following weak points of the assumed simplifications can be noticed:

- usually, conditional probabilities of both errors are different and accumulated error probability depends on quality of the input material;

- in subsequent executions of the loop, usually the entire work is not executed anew, but fragments of the already executed actions are corrected, which should be cheaper;

- in fact, other stop conditions than successful ending also exist - in particular time and budgetary limits; the processes ended with a failure must be also considered at cost estimation.

\subsection{Calculations}

Probability of obtaining a correct result at the output of the loop composed of the tasks Z2-Z3 is given by the formula:

$$
\mathrm{p}_{23}=1-\left(1-\mathrm{p}_{2}\right)\left(1-\mathrm{p}_{3}\right) \text {. }
$$

Expected cost of a loop composed of the tasks Z2-Z2 is given by the formula:

$$
\begin{aligned}
& C(\{Z 2 ; Z 3\})=\sum_{n=0}^{\infty}\left(\left(1-p_{2}\right) p_{3}+p_{2}\left(1-p_{3}\right)\right)^{n}\left(C\left(Z 2, p_{2}\right)+\right. \\
& \left.C\left(Z 3, p_{3}\right)\right), \\
& C(\{Z 2 ; Z 3\})=\frac{C\left(Z 2, p_{2}\right)+C\left(Z 3, p_{3}\right)}{1-\left(\left(1-p_{2}\right) p_{3}+p_{2}\left(1-p_{3}\right)\right)^{\prime}} .
\end{aligned}
$$

Probability of obtaining a correct result at the output of the entire process is given by the formula:

$$
\mathrm{p}_{1234}=1-\left(1-\mathrm{p}_{4}\right)\left(1-\left(\mathrm{p}_{1} \mathrm{p}_{23}\right)\right),
$$

Expected cost of the entire design is given by the formula:

$$
\begin{gathered}
(\{Z 1 ; Z 2 ; Z 3 ; Z 4\})= \\
=\sum_{n=0}^{\infty}\left(\left(1-p_{1} p_{23}\right) p_{4}+p_{1} p_{23}\left(1-p_{4}\right)\right)^{n}\left(C\left(Z 1, p_{1}\right)+\right. \\
\left.\frac{C\left(Z 2, p_{2}\right)+C\left(Z 3, p_{3}\right)}{1-\left(\left(1-p_{2}\right) p_{3}+p_{2}\left(1-p_{3}\right)\right)}+C\left(Z 4, p_{4}\right)\right), \\
C(\{Z 1 ; Z 2 ; Z 3 ; Z 4\})=\frac{C\left(Z 1, p_{1}\right)+\frac{C\left(Z 2, p_{2}\right)+C\left(Z 3, p_{3}\right)}{1-\left(\left(1-p_{2}\right) p_{3}+p_{2}\left(1-p_{3}\right)\right)}+C\left(Z 4, p_{4}\right)}{1-\left(\left(1-p_{1} p_{23}\right) p_{4}+p_{1} p_{23}\left(1-p_{4}\right)\right)} .
\end{gathered}
$$

Planning of the process is aimed at designing all the sub-processes in such a way that total cost is minimised at the condition: $\mathrm{p}_{1234}>\mathrm{p}_{\min }$.

\subsection{Methods of improving precision of the estimates}

For the needs of precise cost estimates of a business process, its detailed structure should be taken into account. When it affects the results significantly, simplifications like those above should be resigned. Probabilities and costs of corrections at planning a new activity must be assumed beforehand, but statistical methods and historical data can be used at improving the processes.

Reduction of costs of single tasks is usually connected with their lower quality, so it not always results in a reduction of total costs. As an example, when using cheaper and less precise methods of determining the requirements, we take the risk that they will be more often wrongly determined, and thus:

- the projects in their mass will less often pass validation, which will result in more frequent necessity of repeating the whole cycle, which generates costs,

- faulty projects will more often positively pass validation, which affects quality of the offer in a negative way.

\subsection{Exemplary design process}

The figure below (figure 6) shows situation of an innovative enterprise acting on the grounds of the agile methods, in that design is separated within the crowdsourcing [10].

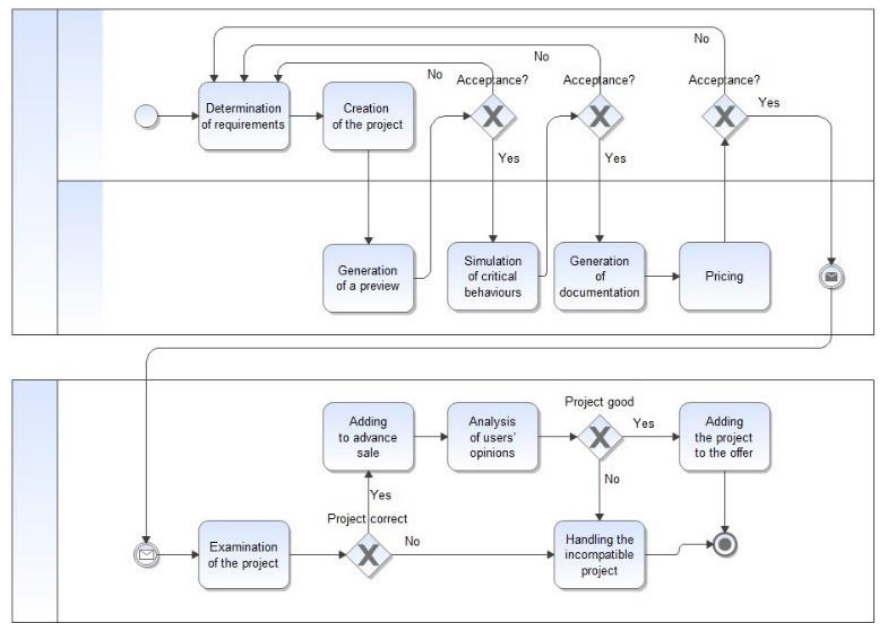

Fig. 6. Map of the design process

A part of errors can be detected thanks to suitable design supporting software, some others can be detected by a company employee - the moderator, and yet others will be detected by the users testing the project at the last "semi-market" stage of validation.

\subsection{Issues of individual adaptation}

The most important matters to be established are:

\section{The tests executed by the software}

With regard to costs of error handling, care should be taken that the tests verify occurrence of possibly large number of errors. Therefore, sequence of creation of individual tests should be decided, first of all, by frequency of the error occurrence. The information required for this purpose can be acquired by making earlier the DFMEA analysis. It can be expected that a large part of the tests will not have $100 \%$ effectiveness, so it can be assumed that the test should return one of the three possible results:

- error - making impossible sending the project to further proceeding,

- warning - informs about a possible error,

- correct result - no error was found.

\section{The aspects checked by the moderator}

The moderator checks the project in respect to the list of warnings and a list of known errors for that no automatic test was created, as well as searching for the errors unknown before. To this end, the moderator can use the same DFMEA analysis mentioned in the subclause above.

\section{Sequence of checking the projects}

To establish a sequence of checking the projects, it is best to by guided by the expected demand for the designed product. This demand can be estimated on the grounds of evaluations of individual customers. This requires publishing the projects before introducing them to sale and gives no guarantee that each customer that gave the project a positive evaluation will be inclined to buy the product created on its base. However, knowing the purchase history and customers' evaluations, probability of making the purchase can be established.

\section{Groups of customers admitted to advance sale}

Advance sale is an opportunity to distinguish a group of customers, because e.g. they will have a possibility to come into possession of the new product before the other customers. Because of increased risk of 
selling defective products, these persons should be loyal to the company of adequately informed about this risk. For example, only these customers should be admitted to advance sale, who made recently purchases of total value above the determined level. In addition, the motivated customers will willingly give us the feedback, in particular if we remind them by sending at suitable intervals e.g. email messages with the related request.

5. Procedures of handling incompatible projects for various incompatibility reasons.

\subsection{Supply chain management}

Activity of an enterprise is not limited only to creation of suggested values, i.e. designing products liked by numerous customers. Equally important is the possibility to deliver these products. Even if the company is a design office only, its final product is a "tool" used by other members of the supply chain for manufacture of a product that constitutes a value for the consumer [19].

It is assumed in the idea presented in this paper that these processes only are executed in the enterprise, whose manufacture within outsourcing is impossible or very difficult. In that connection, role of virtual supply chain will be more important than in the companies holding to other ideas. Selection of partners and ensuring suitable information flow between them will probably strongly influence later operation of the entire supply chain [20], [21], and so also success of the company.

Key issues that are worth to be emphasised before starting activity are:

- principles of cooperating with the partners,

- principles of evaluating the partners,

- criteria of selecting partners, as well the methods of their establishing and modifying

- ways of negotiations,

- information necessary for correct functioning of the supply chain, documents including this information, methods of efficient transferring them [12].

\section{Conclusions}

It can be seen on the grounds of the above deliberations that it is possible to build an enterprise almost free of the processes requiring involvement of costly technical infrastructure. This makes it possible to reduce the capital necessary for starting the business. Apart from removing the risky investment in tangible assets, it was possible to suggest a process with reduced costs of product design, considering at the same time specific customers' requirements in details - including quick determination of production costs thanks to automatic pricing. The cheap production process makes it also possible to reduce the capital necessary for starting the business, since the first products must be designed before the company achieves any incomes.

Reduction of the initial capital has two functions: starting-up the company is easier, sometimes even becomes possible thanks to such a reduction and decreases maximum loss, when proper legal form of the enterprise is selected.

The amount of risk is affected by all the possible scenarios with their results and probability of occurrence. Reduction of the initial capital causes that the pessimistic variant is not terrible, however it is not the only effect of the model reducing the investors' risk. Thanks to outsourcing, reducing technical infrastructure and shifting a part of design costs directly to potential customers in crowdsourcing processes, fixed costs are reduced to a minimum and variable costs are dominating. This causes that the breakeven point is low, so the problems with cost coverage should occur less often, even during periodically smaller demand. The break-even point below that the enterprise starts bearing losses is lower than if the company would try executing these tasks by itself. Therefore, it can be seen that the suggested model accomplishes well the objectives related to reduction of risk

\section{References}

M. Boscoianu, C. Cioaca, V. Vladareanu, and C.-E. Boscoianu, An Active Support Instrument for Innovation in Deep Uncertainty? The Strategic Management Ingredients in Robotics and Mechatronics, Procedia Comput. Sci., vol. 65, pp. 210-217, 2015.

[2] G. Kłosowski and A. Gola, Risk-based estimation of manufacturing order costs with artificial intelligence, presented at the Proceedings of the 2016 Federated Conference on Computer
Science and Information Systems (FEDCSIS), IEEE, 2016, pp. 729732.

[3] A. Bastgen and C. L. Holzner, Employment protection and the market for innovations, Labour Econ., vol. 46, pp. 77-93, Jun. 2017.

[4] M. Relich, A. Świć, and A. Gola, A Knowledge-Based Approach to Product Concept Screening, in Distributed Computing and Artificial Intelligence, 12th International Conference, vol. 373, S. Omatu, Q. M. Malluhi, S. R. Gonzalez, G. Bocewicz, E. Bucciarelli, G. Giulioni, and F. Iqba, Eds. Cham: Springer International Publishing, 2015, pp. 341-348.

[5] R. Falvey, J. Poyago-Theotoky, and K. T. Teerasuwannajak, Coordination costs and research joint ventures, Econ. Model., vol. 33, pp. 965-976, Jul. 2013.

[6] A. Vaxevanou and N. Konstantopoulos, Models Referring to Outsourcing Theory, Procedia - Soc. Behav. Sci., vol. 175, pp. 572 578, Feb. 2015.

[7] G. Giertl, M. Potkany, and M. Gejdos, Evaluation of Outsourcing Efficiency through Costs for its Use, Procedia Econ. Finance, vol. 26, pp. 1080-1085, 2015.

[8] A. Kupczyk, H. Czerwonka-Mróz, and M. Czerwonka, Radical changes in the company - from reengineering to learning organization [in Polish]. Warszawa: Wydawnictwo PrawnoEkonomiczne INFOR, 1998.

[9] A. Tarnowska, Changes in the housing stock and their equipment in rural areas, Hradec Economic Days 2013. Economic Development and Management of Regions, University of Hradec Kralove, t. III, s. 441-445, 2013

[10] C. Anderson, Long tail. Economics of the future - every consumer has a voice [in Polish]. Poznań: Media Rodzina, 2008.

[11] M. Brzozowski, Virtual organization [in Polish]. Polskie Wydawnictwo Ekonomiczne, 2010.

[12] L. Krajewski, L. Ritzman, and M. Malhotra, Operations Management: Processes and Value Chains. Upper Saddle River: Prentice Hall, 2006.

[13] J. Gąbka and S. Susz, Concept of Decision Support System Assisting Dispersed Manufacturing Networks," in Manufacturing 2014: Contemporary Problems of Manufacturing And Production Management, Poznań, 2014, pp. 114-123.

[14] T. Szymczyk, S. Rabiej, and E. Pielesz, Formulas and tables of mathematical, physical, chemical [in Polish]. Bielsko-Biała: Fenix, 2011.

[15] PN-EN ISO 9001:2009, Quality Management Systems Requirements [in Polish]. PKN, Warszawa, 2009.

[16] B. Hoła, Identification and evaluation of processes in a construction enterprise, Arch. Civ. Mech. Eng., vol. 15, no. 2, pp. 419-426, Feb. 2015.

[17] M. Jasiulewicz-Kaczmarek, The role of ergonomics in implementation of the social aspect of sustainability, illustrated with the example of maintenance, [in:] Arezes, $\mathrm{P}$ et al. (eds.) Occupational Safety and Hygiene, CRC Press, Taylor \& Francis: London 2013, pp. 47-52.

[18] M. Sikorski, Man-computer interaction [in Polish]. Warszawa: Polsko-Japońska Wyższa Szkoła Technik Komputerowych, 2010.

[19] J. Gąbka, S. Susz, and E. Chlebus, A concept of advisory system supporting partner selection in virtual organizations, Innov. Prod. Eng. Part V Knowl. Manag. Decis. Support Syst., pp. 349-357, 2012 
[20] K. Grzybowska and A. Lupicka, Knowledge Acquisition in Complex Systems, presented at the Proceedings of the 2016 International Conference on Economics and Management Innovations, part of Advances in Computer Science Research vol 57, 2016, pp. 262266.
[21] K. Grzybowska and B. Gajšek, Supply Chain Logistics Platform as a Supply Chain Coordination Support, in Highlights of Practical Applications of Scalable Multi-Agent Systems. The PAAMS Collection, vol. 616, J. Bajo, M. J. Escalona, S. Giroux, P. HoffaDąbrowska, V. Julián, P. Novais, N. Sánchez-Pi, R. Unland, and R. Azambuja-Silveira, Eds. Cham: Springer International Publishing, 2016, pp. 61-72. 